\title{
АКТУАЛЬНЫЕ ВОПРОСЫ ПРАВОВОГО РЕГУЛИРОВАНИЯ ТЕХНОЛОГИИ ИСКУССТВЕННОГО ИНТЕЛЛЕКТА
}

\section{CURRENT ISSUES IN THE LEGAL REGULATION OF ARTIFICIAL INTELLIGENCE TECHNOLOGY}

\section{A. Kuznetsov}

Summary: The article is devoted to the analysis of the legal regulation of the introduction of digital technologies using the example of artificial intelligence, including for the purposes of national projects. The main current problems and trends in the legal regulation are discussed. Some suggestions are made to increase the efficiency of digitization and minimize new risks.

Keywords: digital technologies, digitalization, legal regulation, artificial intelligence, e-person, robots.
Кузнецов Антон Константинович

к.и.н., дочент, ФГБОУ ВО «Чувашский государственный университет имени И.Н. Ульянова» (г. Чебоксары), kuznetsov-ak@mail.ru

Аннотация: В статье представлен анализ правового обеспечения внедрения цифровых технологий на примере искусственного интеллекта, в том числе в рамках задач реализации национальных проектов. Рассмотрены основные актуальные проблемы и тенденции в регулировании новых правоотношений. Приведены некоторые предложения по повышению эффективности цифровизации и минимизации новых рисков.

Ключевые слова: цифровые технологии, цифровизация, правовое регулирование, искусственный интеллект, электронное лицо, роботы.

по искусственному интеллекту. Апробируются меры по профилактике нарушений порядка проведения единого государственного экзамена в России с использованием искусственного интеллекта: поведенческий анализ участников экзаменов на основе нейронных сетей и распознавание почерков (сравнение сканированных копий экзаменационных работ и итоговых сочинений выпускников).

Ускорение внедрения технологических решений обусловлено рядом факторов:

- общий («сквозной») характер применения прикладных технологических решений, разработанных на основе искусственного интеллекта;

- высокая степень влияния технологических решений, разработанных на основе искусственного интеллекта, на результативность деятельности организаций и человека, в том числе связанной с принятием управленческих решений;

- высокая доступность инструментов (в том числе программ для ЭВМ с открытым кодом) для разработки на основе искусственного интеллекта технологических решений;

- потребность в обработке больших объемов данных, создаваемых как человеком, так и техническими устройствами, для повышения эффективности экономической и иной деятельности [4].

Под термином «искусственный интеллект» авторы Национальной стратегии развития искусственного интеллекта на период до 2030 года понимают комплекс технологических решений, позволяющий имитировать 
когнитивные функции человека (включая самообучение и поиск решений без заранее заданного алгоритма) и получать при выполнении конкретных задач результаты, сопоставимые, как минимум, с результатами интеллектуальной деятельности человека. Комплекс технологических решений включает в себя информационно-коммуникационную инфраструктуру, программное обеспечение (в том числе в котором используются методы машинного обучения), процессы и сервисы по обработке данных и поиску решений.

Технологии искусственного интеллекта - это технологии, основанные на использовании искусственного интеллекта, включая компьютерное зрение, обработку естественного языка, распознавание и синтез речи, интеллектуальную поддержку принятия решений и перспективные методы искусственного интеллекта [4].

Необходимо отметить, что на сегодня Российская Федерация использует дефиниции международного стандарта ISO 8373:2012 «Роботы и робототехнические устройства. Словарь», который был принят в России в качестве национального стандарта ГОСТ Р 60.0.0.4-2019/ ИСО 8373:2012 «Роботы и робототехнические устройства. Термины и определения» [7].

В соответствии с паспортом национального проекта «Национальная программа «Цифровая экономика Российской Федерации» в 2020-2021 гг. запланировано формирование отраслевого регулирования правоотношений в сфере робототехники и применения технологий искусственного интеллекта, разработка и реализация стандартов информационной безопасности в системах, реализующих облачные, туманные, квантовые технологии, в системах виртуальной и дополненной реальности, и технологии искусственного интеллекта [6].

Несмотря на поставленные задачи формирования правового поля внедрения и использования цифровых технологий, данный вопрос остается актуальным. Важным представляется соблюдение баланса между интересами общества, которые заключаются в самом широком использовании новых технологий для решения различных проблем, а с другой стороны, необходимостью минимизации негативных последствий использования инноваций. П.М. Морхат выделяет проблемы стандартизации искусственного интеллекта, лицензирования, обеспечения конфиденциальности персональных сведений и личной информации, обеспечения соблюдения норм профессиональной этики [2].

А.В. Минбалеев считает, что среди основных тенденций в регулировании использования искусственного интеллекта выделяются следующие:

- сочетание различных механизмов социального регулирования использования искусственного интеллекта (правового, этического, технического, локального и иных механизмов регулирования, саморегулирования и сорегулирования, а также их синтез; создание принципиально новых синтезированных механизмов регулирования, основанных на многоуровневой командной системе действия норм);

- обязательность обеспечения безопасности человека и его прав при использовании искусственного интеллекта, исключение рисков уничтожения человечества;

- сочетание концептуального регулирования всестороннего использования искусственного интеллекта и регулирование наиболее острых, требующих немедленного решения проблем по отдельным технологиям искусственного интеллекта (беспилотный транспорт, использование роботов в сфере услуг, телемедицина, обработка больших данных, навигация и др.);

- неоднозначность восприятия систем искусственного интеллекта и роботов с позиции права (начиная от использования режима «рабов человека» и до приравнивания прав роботов к правам человека и созданию электронных лиц как субъектов права);

- необходимость решения этических проблем использования искусственного интеллекта и робототехники [1].

24 апреля 2020 г. был опубликован Федеральный закон № 123-Ф3 «О проведении эксперимента по установлению специального регулирования в целях создания необходимых условий для разработки и внедрения технологий искусственного интеллекта в субъекте Российской Федерации - городе федерального значения Москве и внесении изменений в статьи 6 и 10 Федерального закона «О персональных данных» [3].

Законом предусматривается проведение в городе Москве эксперимента по установлению с 1 июля 2020 г. специального правового регулирования в целях создания необходимых условий для разработки и внедрения технологий искусственного интеллекта, а также последующего использования результатов его применения. Согласно закону, срок проведения эксперимента составит пять лет.

Важно, что понимание необходимости правового регулирования новых правоотношений и новых рисков нашло отражение в инициативах по внесению изменений в Основной закон. Так, в соответствии с Законом Российской Федерации о поправке к Конституции Российской Федерации от 14.03.2020 № 1-ФК3 «О совершенствовании регулирования отдельных вопросов организации и функционирования публичной власти» в статью 71, 
которая определяет вопросы ведения Российской Федерации, внесены дополнения в части «обеспечения безопасности личности, общества и государства при применении информационных технологий, обороте цифровых данных» [5].

Таким образом, в целях дальнейшего развития электронного (открытого) правительства, инновационного здравоохранения, цифровой экономики, «умного» транспорта, а также других национальных проектов важным представляется решение вопросов правового регулирования новых правоотношений и возможных негативных последствий, возникающих при внедрении цифровых технологий.
В ходе широкой научной дискуссии предлагается обсудить максимально возможный спектр вопросов: выработка единых подходов к терминологическому аппарату, определение модели правового регулирования искусственного интеллекта (особый вид имущества, юридическое лицо, «электронное лицо» как новая правовая категория и др.), обеспечение безопасности персональных данных, обязательное страхование роботов их владельцами и производителями, правовой статус роботов-агентов, защита и безопасность пользователей, этические нормы и много другое. Кроме того, важным представляется создание экспериментальных правовых режимов, а также анализ и обобщение опыта зарубежных коллег.

\section{ЛИТЕРАТУРА}

1. Минбалеев А.В. Проблемы регулирования искусственного интеллекта // Вестник ЮУрГУ. Серия «Право». - 2018. - Т. 18, № 4. - С. 85.

2. Морхат П.М. К вопросу о специфике правового регулирования искусственного интеллекта и о некоторых правовых проблемах его применения в отдельных сферах // Закон и право. 2018. №6. // URL: https://cyberleninka.ru/article/n/k-voprosu-0-spetsifike-pravovogo-regulirovaniya-iskusstvennogo-intellekta-i0-nekotoryh-pravovyh-problemah-ego-primeneniya-v-otdelnyh (дата обращения: 20.04.2020).

3. 0 проведении эксперимента по установлению специального регулирования в целях создания необходимых условий для разработки и внедрения технологий искусственного интеллекта в субъекте Российской Федерации - городе федерального значения Москве и внесении изменений в статьи 6 и 10 Федерального закона «0 персональных данных: Федеральный закон от 24.04.2020 № 123-Ф3 // URL: http://publication.pravo.gov.ru/Document/View/00 01202004240030?index=0\&rangeSize $=1$ (дата обращения: 01.05.2020).

4. 0 развитии искусственного интеллекта в Российской Федерации (вместе с «Национальной стратегией развития искусственного интеллекта на период до 2030 года»): Указ Президента Российской Федерации от 10.10.2019 № 490 // СЗ РФ, 14.10.2019, № 41, ст. 5700.

5. 0 совершенствовании регулирования отдельных вопросов организации и функционирования публичной власти: Закон Российской Федерации 0 поправке к Конституции Российской Федерации № 1-ФК3 от 14.03.2020 // URL: http://publication.pravo.gov.ru/Document/View/0001202003140001 (дата обращения: 20.04.2020).

6. Паспорт национального проекта «Национальная программа «Цифровая экономика Российской Федерации», утв. президиумом Совета при Президенте РФ по стратегическому развитию и национальным проектам, протокол от 04.06.2019 № 7 // URL: https://digital.gov.ru (дата 0бращения: 20.04.2020).

7. IS0 8373:2012. «Роботы и робототехнические устройства. Словарь». // URL: https://www.iso.org/standard/55890.html (дата 0бращения: 20.04.2020); ГOCT P 60.0.0.4-2019/ИC0 8373:2012 «Роботы и робототехнические устройства. Термины и определения» // URL: http://docs.cntd.ru/document/1200162703 (дата обращения: 20.04.2020).

(c) Кузнецов Антон Константинович (kuznetsov-ak@mail.ru). 